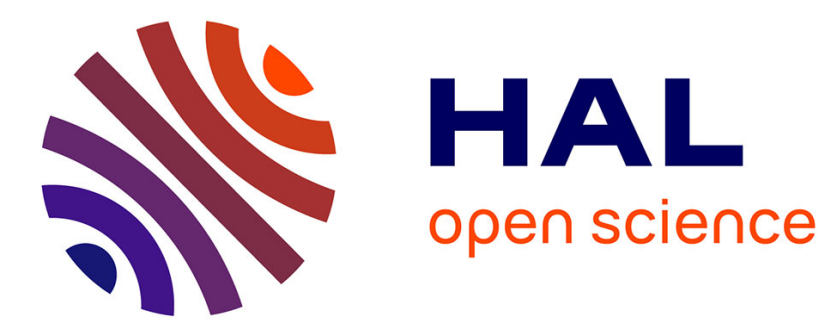

\title{
ATOM-PROBE STUDY OF ALUMINIUM-LITHIUM ALLOYS
}

\author{
A. Menand, T. Al Kassab, S. Chambreland, J. Sarrau
}

\section{To cite this version:}

A. Menand, T. Al Kassab, S. Chambreland, J. Sarrau. ATOM-PROBE STUDY OF ALUMINIUM-LITHIUM ALLOYS. Journal de Physique Colloques, 1988, 49 (C6), pp.C6-353-C6358. 10.1051/jphyscol:1988661 . jpa-00228158

\section{HAL Id: jpa-00228158 https://hal.science/jpa-00228158}

Submitted on 1 Jan 1988

HAL is a multi-disciplinary open access archive for the deposit and dissemination of scientific research documents, whether they are published or not. The documents may come from teaching and research institutions in France or abroad, or from public or private research centers.
L'archive ouverte pluridisciplinaire HAL, est destinée au dépôt et à la diffusion de documents scientifiques de niveau recherche, publiés ou non, émanant des établissements d'enseignement et de recherche français ou étrangers, des laboratoires publics ou privés. 
JOURNAL DE PHYSIQUE

Colloque C6, supplément au $\mathrm{n}^{\circ} 11$, Tome 49, novembre 1988

ATOM-PROBE STUDY OF ALUMINIUM-LITKIUM ALLOYS

A. MENAND, T. AL KASSAB*, S. CHAMBRELAND and J.M. SARRAu

Laboratoire de Microscopie Ionique, CNRS UA-808, Faculté des Sciences de Rouen, BP 118, F-76134 Mont-Saint-Aignan Cedex, France

*Institut für Metallphysik der Universität Göttingen, D-3400 Göttingen, F.R.G.

Abstract - We analysed Al-Li based alioys by means of atom-probe. The influence of parameters such as the tip temperature and the pulse fraction on the apparent composition were investigated for an Al-2.7at\%Li alloy and for an Al-7.5at\%Li-1.2at\%Cu alloy. A ternary A1-3.5wt\%Li-3.6wt\%Mg alloy aged $24 \mathrm{~h}$ at $190^{\circ} \mathrm{C}$ was studied. Atom-probe results point out the presence of $\mathrm{Mg}$ in the $\delta^{\prime}$ phase.

\section{I - INTRODUCTION}

The Al-Li based alloys have been intensively studied in the past few years as light weight and high modulus aerospace materials. A few atom-probe investigations have been reported $/ 1 /, / 2 /$. The ability of performing quantitative A.P. analyses of Al-Li based alloys was discussed at the last OSAKA IFES and is still an open question. The aim of this paper is to contribute to clarify this problem and to determine the best analysis conditions.

As Al-Li alloys decompose at room temperature for Li content higher than 5 at\%, we investigated the influence of the tip temperature and of the pulse fraction on the apparent lithium concentration in an Al-2.7at:Li alloy. Then we subsequently analysed an Al-Li-Cu alloy with higher $\mathrm{Li}$ content 7.5 at\% and an Al-Li-Mg alloy with $\delta^{\prime}$ precipitates.

\section{II - EXPERIMENTAL}

The FIM specimen were prepared by anodic electropolishing at 5-7 volts DC in a solution of $2 / 3$ methanol and $1 / 3$ nitric acid cooled at $-40^{\circ} \mathrm{C}$ with a circulation of the electrolyte produced by the same system as the one developed for titanium specimen preparation $/ 3 /$.

The atom-probe used in this study is a conventional one described elsewhere $/ 4 /, / 5 /$. FIM images were observed at $20 \mathrm{~K}$ with pure Neon as imaging gas. Atom-probe analyses were performed in a good vacuum of $2.10^{-10}$ Torr at temperatures between $20 \mathrm{~K}$ and $80 \mathrm{~K}$ with a pulse ratio of 0.1 to 0.2 and a pulse repetition rate of $40 \mathrm{~Hz}$.

III - RESULTS AND DISCUSSION

\section{Al-2.7at:Ii}

Fig. 1 shows a mass spectrum of an Al-2.7at\%Li alloy obtained at $20 \mathrm{~K}$ with a $20 \%$ pulse fraction. The aluminium is detected in a proportion of $90 \%$ as singly charged ions. The lithium level for this analysis is 3.1 at\%.

Fig. 2 summarizes the results obtained over 12 samples and 150000 ions in different temperature and pulse ratio conditions. The error bars are taken as one standard deviation. This figure exhibits a clear dependence of the apparent lithium concentration with respect to the temperature. The observed concentration decreases as temperature increases. The dependence on 
pulse fraction is more complex. At $20 \mathrm{~K}$ no clear dependence appears while the Iithium level decreases with the pulse fraction for $30 \mathrm{~K}$ and $40 \mathrm{~K}$. The dashed Iine corresponds to the nominal concentration $2.7 \%$. This composition is only obtained for $30 \mathrm{~K}$ and a pulse ratio between $15 \%$ and $20 \%$. In fact, two phenomena interfere : the preferential evaporation of lithium atoms enhanced at higher temperature and the "pile up" effects for aluminium more prononced at low temperature because of a burst field evaporation behaviour.

"Pile up" effects were first investigated by TsoNG et al /6/ who assumed that the number of ions per pulse follows a Poisson distribution. This implies the evaporation of atoms to be a time randomly distributed process which is generally not the case. More recently CEREzo et al /7/ developed a statistical correction without making any prior assumption as to the distribution of ions per pulse. They calculated from a multinomial distribution the theoretical probabilities of events when "pile up" occurs and corrected the apparent concentrations. In a similar way we use a very simple method the advantage of which is to make use of an experimental data i.e. the observed double events ratio $k_{d} / 8 /$ with $k_{d}=N_{d} / N_{T}$ where $N_{d}$ is the number of observed double events and $\mathrm{N}_{T}$ the total number of detected ions. This method gives a first order correction and can be extended to a triple events correction.

Considering a spectrum with $n$ peaks the relative abundance of which is $P_{i}$ and assuming a chemically desordered coevaporation process (well suited for a randomly distributed solid solution), the proportion of ii type real double events is $\sum_{i=1}^{n} P_{i}^{2}$ while the proportion of $i j$ type double events is $1-\sum_{i=1}^{n} P_{i}^{2}$. If all the $i i$ type double events are considered as giving a pile up effect, the lost double events ratio $T$ writes :

$$
\tau=\frac{\sum_{i=1}^{n} P_{i}^{2}}{1-\sum_{i=1}^{n} P_{i}^{2}}
$$

while the partial ratio of lost double events for a species $x$ existing in the spectrum with $n_{x}$ peaks is :

$$
\tau_{x}=\frac{\sum_{i=1}^{n_{x}} P_{i}^{2}}{1-\sum_{i=1}^{n} P_{i}^{2}}
$$




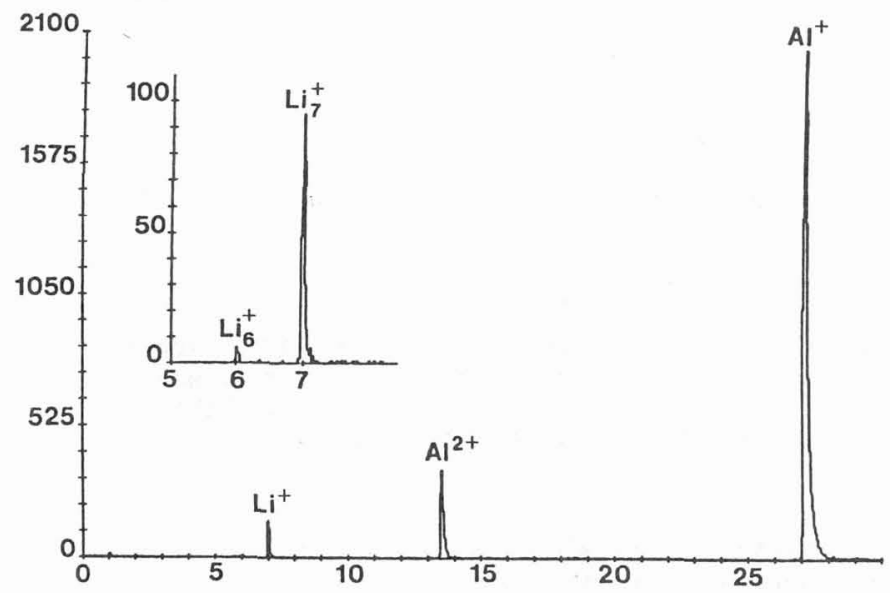

Fig. 1 - Atom-probe mass spectrum of an Al-2.7at\%Li alloy.

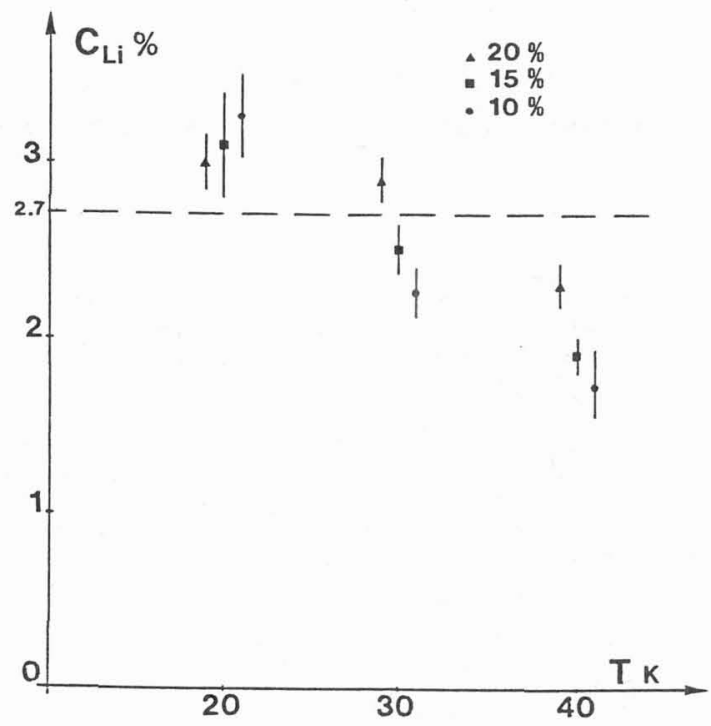

Fig. 2 - Apparent lithium composition as a function of temperature for three pulse fractions. 
Then using the experimental value $k_{d}$, the corrected concentrations $c^{*}$ are decuced from the observed concentrations $c^{\circ}$ :

$$
C_{x}^{*}=\frac{C_{x}^{0}}{1+\tau k_{d}}+\frac{\tau_{x} k_{d}}{1+\tau k_{d}}
$$

gives :

for low concentration species the second term is negligible which

$$
C_{x}^{*}=C_{x}^{0} /\left(1+T k_{d}\right)
$$

With $k_{d}=3 \%$, (a typical value in our experiments), and $\tau=3.3$ calculated from the peaks distribution of Fig. 1, the apparent concentration which is predicted is $C=2.97 \%$. In fact the shift may be slightly larger taking in account a second order correction with the triple events.

\section{Al-Li-Cu}

Table 1 gives the results obtained at different temperatures with a $20 \%$ pulse ratio for a specimen of $\mathrm{Al}-\mathrm{Li}-\mathrm{Cu}$ alloy.

\begin{tabular}{|c|c|c|c|}
\hline $\mathrm{T}$ & $\mathrm{Al}$ at $\%$ & Li at $\%$ & $\mathrm{Cu}$ at $\%$ \\
\hline $20 \mathrm{~K}$ & $91.73 \pm 0.5$ & $7.25 \pm 0.5$ & $1.02 \pm 0.2$ \\
\hline $40 \mathrm{~K}$ & $92.5 \pm 0.2$ & $6.6 \pm 0.2$ & $0.93 \pm 0.1$ \\
\hline $80 \mathrm{~K}$ & $95.3 \pm 0.2$ & $3.2 \pm 0.2$ & $1 \pm 0.1$ \\
\hline $\begin{array}{c}\text { nominal } \\
\text { composition }\end{array}$ & 91.3 & 7.5 & 1.2 \\
\hline
\end{tabular}

Table 1.- Observed compositions as a function of temperature

The results are in reasonable agrement for $20 \mathrm{~K}$ with the nominal. composition while the lithium level is more than a factor 2 too low for $80 \mathrm{~K}$.

\section{Al-Li-Mg}

We analysed samples of an Al-3.5wt\%Li-3.6wt\%Mg homogenised then aged for $24 \mathrm{~h}$ at $190^{\circ} \mathrm{C}$. This treatment leads to spherical $\delta^{\prime}$ precipitates the size of which ranges between $300 \AA$ and $600 \AA$. The atom-probe analyses were performed at $20 \mathrm{~K}$ with a $20 \%$ pulse fraction. As shown in Fig. 3 the magnesium is detected as doubly charged ions.

The concentration profiles of Fig. 4 correspond to the crossing of two $\delta^{\prime}$ precipitates. The lithium level reaches 17.5 at\% in these particles. These profiles also point out the presence of magnesium in the $\delta$, precipitates which, until now, was a question of controversy. Table 2 gives the matrix and precipitate compositions we obtained, the error bars are taken as one standard deviation.

\begin{tabular}{|c|c|c|c|}
\hline & $\mathrm{Al}$ & $\mathrm{Li}$ & $\mathrm{Mg}$ \\
\hline matrix & $91.5 \pm 0.3$ & $6.3 \pm 0.3$ & $2.2 \pm 0.2$ \\
\hline precipitates & $77.6 \pm 0.5$ & $17.5 \pm 0.5$ & $4.9 \pm 0.3$ \\
\hline
\end{tabular}

Table 2.- Matrix and precipitates compositions 


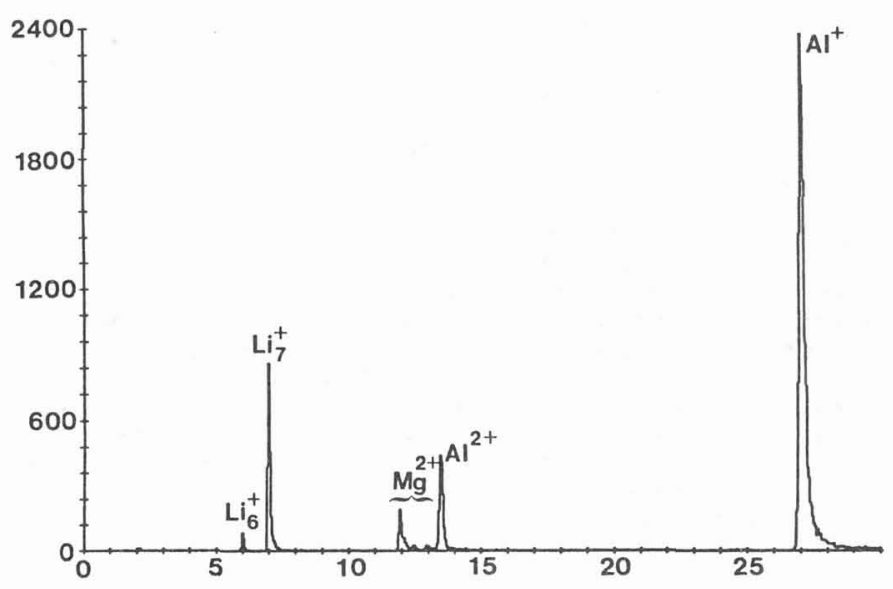

Fig. 3 - Atom-probe mass spectrum of an Al-3.5wt:Li-3.6wt\%Mg alloy.

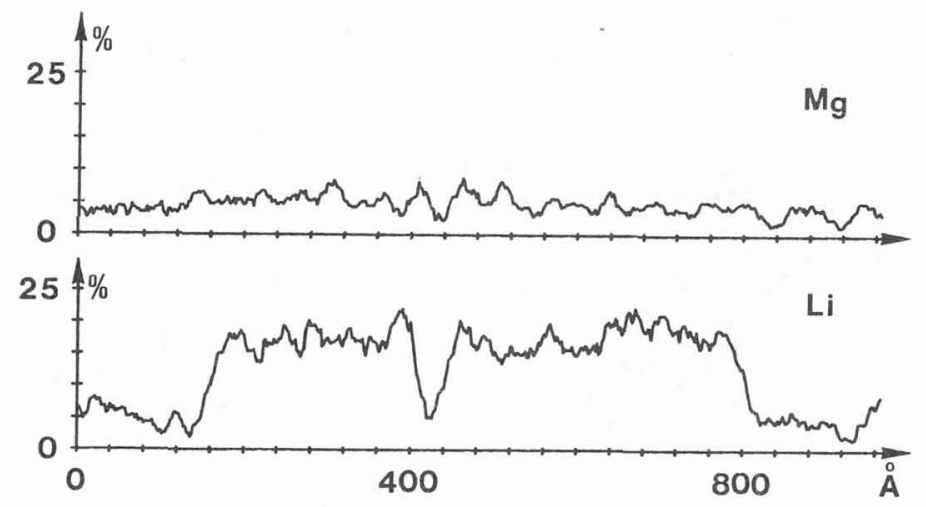

Fig. 4 - Concentration profiles of an Al-3.5wt\%Li-3.6wt\%Mg aged $24 \mathrm{~h}$ at $190^{\circ} \mathrm{C}$.

According to the Al-Li phase diagram as suggested by Gayle and vandersande $/ 9 /$, the lithium content in $\delta$, precipitates at $190^{\circ} \mathrm{C}$ is 22.5 at\%. Assuming that the magnesium atoms occupy the lithium sites in the $\mathrm{L}_{2}$ ordered structure (which is a reasonable assumption because the same $\mathrm{Al}_{3} \mathrm{Mg}$ structure exists for the binary Al-Mg) our results agree well with this value. of course the addition of a third element can modify the solubility limits so that we cannot be certain we actually obtained the right lithium level. 


\section{CONCLUSION}

our results demonstrate the feasibility of quantitative analyses for low content $A l-I i$ alloys (up to 8 at\%). The best experimental conditions are : a good vacuum $<3.10^{-10}$ Torr, a low temperature between $20 \mathrm{~K}$ and $30 \mathrm{~K}$ and a pulse fraction greater than $15 \%$. At present the possibility to perform quantitative analyses of $\delta^{\prime}$ precipitates is not completely proved, further experiments are needed to conclude on that point.

During our analyses the best results were obtained at higher evaporation rate whatever the other parameters were. This is certainly a crucial parameter. Our experiments were performed at an average ion rate between 0.02 ion per pulse and 0.03 ion per pulse. In fact for this problem the important parameter is not this average ion number per pulse (which depends on the analysis area) but the actual time which is required for a layer to be desorbed. The preferential evaporation rate is directly related to the life time of atoms at DC field. In order to minimize preferential field evaporation effects this life time has to be much larger than the time required to get one layer. The shorter this latter is, the more reduced the preferential evaporation effects will be.

\section{ACRNOLEDGEMENTS}

We wish to thank Dr G. IAAPASST from ONERA and Dr P. SAINFORT from PECHINEY for providing the samples and for helpful discussions.

\section{REFERENCES}

/1/ ABE T., HONO K., HASHIZUME T., JIMBO A., CARINCI G.M., HESS D.R., SATOH T., HIRANO K., SAKURAI T. and PICKERING H.W., J. de PhYs., $\underline{47-C 2}$ (1986) 185 .

12/ SAKURAI T., KOBAYASHI A., HASEGAWA Y., SAKAI A. and PICKERING H.W., Scripta Met., $\underline{20}$ (1986) 1131 .

13/ HADJADJ L., MENAND A., BLAVETTE D. J J. de Phys., 47-C7 (1986) 281.

/4/ MARTIN C., BLAVETTE D. and SARRAU J.M., Rev. de Phys. Appl., 19 (1984) 27.

/5/ BOSTEL A., BOUET M., and SARRAU J.M., J. de Phys., 47-C7 (1986) 521 .

/6/ TSONG T.T., NG Y.S. and KRISHNASWAMY S.V., Appl. Phys. Lett., 32 (1978) 778 .

/7/ CEREzo A., SMITH G.D.W. and WAUGH A.R., J. de Phys., 45-C9 (1984) 329.

/8/ BLAVETTE D., Thèse d'Etat, ROUEN (1986).

$19 /$ GAYLE F.W. and VANDERSANDE J.B., in Al-Li alloys III (ed. C Baker et al), LONDON, The Institute of Metals (1986) 376 